\title{
Developmental Constraints Adversely Affecting New Entrants Into the Construction Industry of the Limpopo Province of South
} Africa

\author{
Lawrence Tshivhase, Zeleke Worku \\ Tshwane University of Technology Business School, Pretoria, South Africa
}

\begin{abstract}
Although political transformation has occurred in South Africa in April 1994, the pace at which economic transformation has occurred has been slow. A review of the literature has shown that economic transformation has been slowed by an acute shortage of technical skills among Black South Africans working in business, government, and industry. A case in point is the construction industry of Limpopo Province of South Africa in which emerging contractors have failed to compete adequately with well-established contractors in the construction industry due to shortage of technical skills, capital, and lack of access to markets. The study is based on a random sample of 104 emerging contractors operating in the Province of Limpopo. A combination of quantitative and qualitative methods of data collection and analyses was used in the study in order to identify and quantify key obstacles to growth and development in emerging contractors. Eigen values estimated from factor analysis showed that the viability of emerging contractors in the construction industry of Limpopo Province was significantly influenced by three factors (lack of entrepreneurial skills, lack of capital, and lack of transparency in the award of construction tenders). Based on results obtained from multilevel analysis, differences among the five districts of Limpopo Province accounted for $13.18 \%$ of the total variation in viability. Differences in entrepreneurial skills between viable and non-viable businesses accounted for $33.49 \%$ of total variation. Findings of the study show that entrepreneurial skills are no less important than financial capital for ensuring viability in emerging contractors currently operating in Limpopo Province. The study has also found that the fundamental principles of good governance such as transparency and accountability are not adhered to in the administration and award of government tenders, and that this predicament was working to the detriment of emerging contractors in the province.
\end{abstract}

Keywords: Limpopo Province, emerging contractors, construction industry, viability, entrepreneurial skills, odds ratio

\section{Background of Research Problem}

Before April 1994 the construction industry in Limpopo Province was deeply fragmented and almost entirely controlled by white companies. Although there has been some improvement since the new political

Lawrence Tshivhase, Doctoral Student, Tshwane University of Technology Business School.

Zeleke Worku, Associate Professor, Tshwane University of Technology Business School.

Correspondence concerning this article should be addressed to Zeleke Worku, Tshwane University of Technology Business School, Pretoria, South Africa. E-mail: workuz@tut.ac.za. 
dispensation of April 1994 construction firms that are wholly owned by black South Africans are still characterized by a low level of technical skills, inability to compete with established contractors, lack of capital finance, lack of heavy machinery and construction equipment, and lack of support from the Limpopo Provincial Government in terms of capacity building (Tshivhase, 2007). Ncwadi and Dangalazana (2005) have shown that easy access to finance and the presence of engineering-related technical skills are critical requirements in companies that enter the market with a view to compete with well-established construction firms.

The study conducted by Smith, Oosthuizen, Harris, Venter, Combrink, and Roodt (2012) has found that traditional methods used for construction-related engineering and systems applications must be transformed into modern methods and applications in order for improving efficiency and viability in construction firms operating in South Africa. The authors argue that failure to do so has the potential for crippling growth in engineering skills, ultimately leading to the collapse of firms. Due to the neglect of infrastructural development prior to April 1994, black entrepreneurs in Limpopo Province were by and large poorly equipped for competing favourably in large scale construction and engineering projects. There remains a significant backlog in infrastructural development across all sectors of construction. The Provincial Government of Limpopo has a commitment to addressing backlogs in infrastructural development in the construction industry. This in turn presents an opportunity for construction firms in Limpopo Province to compete for such projects. However, it is essential to have the necessary capital and expertise to win such construction projects.

\section{Problem Statement}

Due to the legacies of apartheid-era practices which prohibited black-owned enterprises from developing advanced construction experience, the South African construction industry is currently characterized by stark differences between white- and black-owned construction enterprises with regards to engineering related skills, capital, and access to market (Human, 2006). The huge gap between black and white entrepreneurs in the construction industry in the Limpopo Province is attributed to the inferior quality of education available to the majority of black South Africans. Despite massive efforts have been made since April 1994 there are still rampant challenges that hinder sustainable development in small- and medium-sized enterprises owned by black contractors in the construction industry of Limpopo Province.

\section{Literature Review}

It can be seen from Table 1 that the majority of black contractors in the construction industry of Limpopo Province have low Construction Industry Development Board (CIDB) grades mostly due to their low level of skills and capital. High CIDB grades are essential for competing for large construction projects. The grades vary from one to nine. CIDB grades of five or above are essential for winning sustainable construction contracts. The table shows that black contractors are fairly well represented in CIDB grades of two to seven, and yet do not have sustainable growth and development. As a result, they lack viability in their ever-changing and highly competitive environment in which they operate. The fundamental emphasis is the viability of these contractors at all times. This also considers improving their CIDB status manifesting enhanced competencies to deliver on a much bigger contracts than before by black-owned contractors in the construction industry of Limpopo Province.

It can be seen in Table 1 that 95\% of black-owned construction enterprises have a CIDB grade of two, 
which is quite low, and does not enable them to tackle moderately sized construction projects. With a CIDB grade of two, black entrepreneurs fall under the general building category of CIDB, and only qualify for low level construction projects that are not sustainable. It can also be seen from the table that only $15 \%$ of CIDB grade 9 construction companies are black-owned. Grade 9 construction companies can compete for large scale or national construction projects. This shows that black-owned construction companies in Limpopo Province can only have access to $15 \%$ of large-sized construction projects due to their low CIDB grading. The corresponding figure for white-owned construction companies is $85 \%$. Accordingly, large construction projects are often awarded to white-owned construction companies. This study aims to find out the basic reasons why this discrepancy is still so large, and attempts to identify feasible remedial actions so that the gap could be made smaller.

Table 1

Black Ownership of Construction Firms in South Africa

\begin{tabular}{lllllll}
\hline $\begin{array}{l}\text { CIDB } \\
\text { grade }\end{array}$ & $\begin{array}{l}\text { General } \\
\text { building } \\
(\mathrm{GB})(\%)\end{array}$ & $\begin{array}{l}\text { Civil } \\
\text { engineering } \\
\text { (CE) (\%) }\end{array}$ & $\begin{array}{l}\text { Electrical engineering } \\
\text { work-building (EB) (\%) }\end{array}$ & $\begin{array}{l}\text { Electrical engineering } \\
\text { work-infrastructure } \\
(\mathrm{EP})(\%)\end{array}$ & $\begin{array}{l}\text { Mechanical } \\
\text { engineering } \\
\text { (ME) (\%) }\end{array}$ & $\begin{array}{l}\text { Specialized } \\
\text { works } \\
(\mathrm{SW})(\%)\end{array}$ \\
\hline 2 & 95 & 93 & 81 & 72 & 67 & 78 \\
3 & 93 & 91 & 74 & 62 & 51 & 65 \\
4 & 85 & 82 & 75 & 49 & 43 & 48 \\
5 & 84 & 79 & 56 & 54 & 46 & 47 \\
6 & 75 & 67 & 63 & 57 & 41 & 36 \\
7 & 64 & 45 & 55 & 22 & 35 & 27 \\
8 & 46 & 8 & 50 & 10 & 6 & 5 \\
9
\end{tabular}

Note. Source: CIDB, 2010.

Construction firms that are owned by black entrepreneurs in the Province of Limpopo need massive assistance in order to catch up with white-owned firms in the same province. Black-owned firms have so far failed to compete with white-owned firms in terms of winning large or national projects. This study hopes to shed light on factors that affect the performance of black-owned construction firms with a view to identifying the numerous constraints that adversely affect the growth and financial viability of black-owned construction enterprises.

Table 2 shows the number of jobs created by the South African construction industry. It can be seen from the table that large construction companies account for the majority of jobs created (35.27\%) in the construction industry. This demonstrates that the size of a construction company determines the number of jobs the company is able to create. This suggests that the construction company is dominated by large enterprises that have the financial resources for employing a large number of employees in comparison with micro-, small-, and medium-sized enterprises (SMEs). This grim reality implies that access to markets in the construction industry is also dominated by large enterprises. It follows that SMEs in the construction industry have a rather poor prospect for growth and development in comparison with large enterprises. These entities are unable to compete with large enterprises due to their low CIDB grading, shortage of capital, limited cash flow, and poor engineering-related skills (Thwala \& Phaladi, 2009). Although SMEs jointly generate $64.73 \%$ of all jobs 
created in the construction industry, their growth potential is low due to the restricted access they have to large scale construction projects. The study conducted by Smit and Watkins (2012) shows that the SME sector is not given adequate support and recognition although it contributes significantly to the overall South African economy. According to Human (2006), the poor plight of SMEs in the construction industry is attributable to lack of strategic support, poor capital, and poor engineering-related technical skills.

Table 2

Number of Jobs Created by the South African Construction Industry

\begin{tabular}{lllll}
\hline Large enterprise & Medium enterprise & Small enterprise & Micro enterprise & Total \\
\hline 190,681 & 126,804 & 55,476 & 167,620 & 540,581 \\
\hline
\end{tabular}

Note. Source: Statistics South Africa, 2007.

\section{Objectives of the Study}

The study aims to investigate the reasons why contractors with CIDB grades of two to seven face difficulties that ultimately result in poor financial standing and inability to compete favourably with well-established firms. The study has the following two objectives:

- To identify and quantify factors that adversely affect the performance of emerging contractors in the Limpopo Province;

- To suggest suitable interventions for promoting viability in emerging contractors in the construction industry of Limpopo Province.

\section{Research Questions}

The study has the following two research questions:

- What are the key determinants of viability and success in emerging contractors operating in the construction industry of Limpopo Province?

- What is the degree to which viability in emerging contractors varies depending on geographical district and level of entrepreneurial skills?

\section{Methods and Materials of Study}

The study was conducted by using a combination of quantitative and qualitative methods of data collection and analyses. The design of the study was descriptive and cross-sectional. As part of the quantitative aspect of the study, a random sample of size $n=104$ emerging contractors operating in Limpopo Province was selected for the study. Stratified random sampling was used for selecting eligible contractors for the study. Stratification was done by geographical district (there are five districts in Limpopo Province). Pearson's chi-square tests of association (Dawson \& Trapp, 2004) were used for performing cross-tab analyses. Binary logistic regression analysis (Hosmer \& Lemeshow, 2002) was used for estimating odds ratios for influential predictor variables. Factor analysis (Field, 2010) was used for performing data reduction based on Eigenvalues. Multilevel analysis (Rabe-Hesketh \& Skrondal, 2008) was used for assessing the extent of variability at the levels of districts and entrepreneurial skills. Quantitative data were collected by using a structured, pre-tested, and validated questionnaire of study. Qualitative data were gathered by using in-depth interviews. Qualitative data analysis was performed by using tallying, coding, text analysis, and triangulation. 


\section{Results of Analysis}

\section{Characteristics of Emerging Contractors}

Figure 1 shows a graphical depiction of the duration of survival of emerging contractors operating in the construction industry of Limpopo Province. The graph shows that $49.04 \%$ of contractors have been in the construction business for six to 10 years. The graph also shows that $12.5 \%$ of contractors have managed to survive for 11 to 15 years in operation. Contractors that have existed for three to five years accounted for 33.65\%. These contractors are regarded as newcomers in the industry and are primarily faced with many challenges that adversely affect their viability and long-term survival.

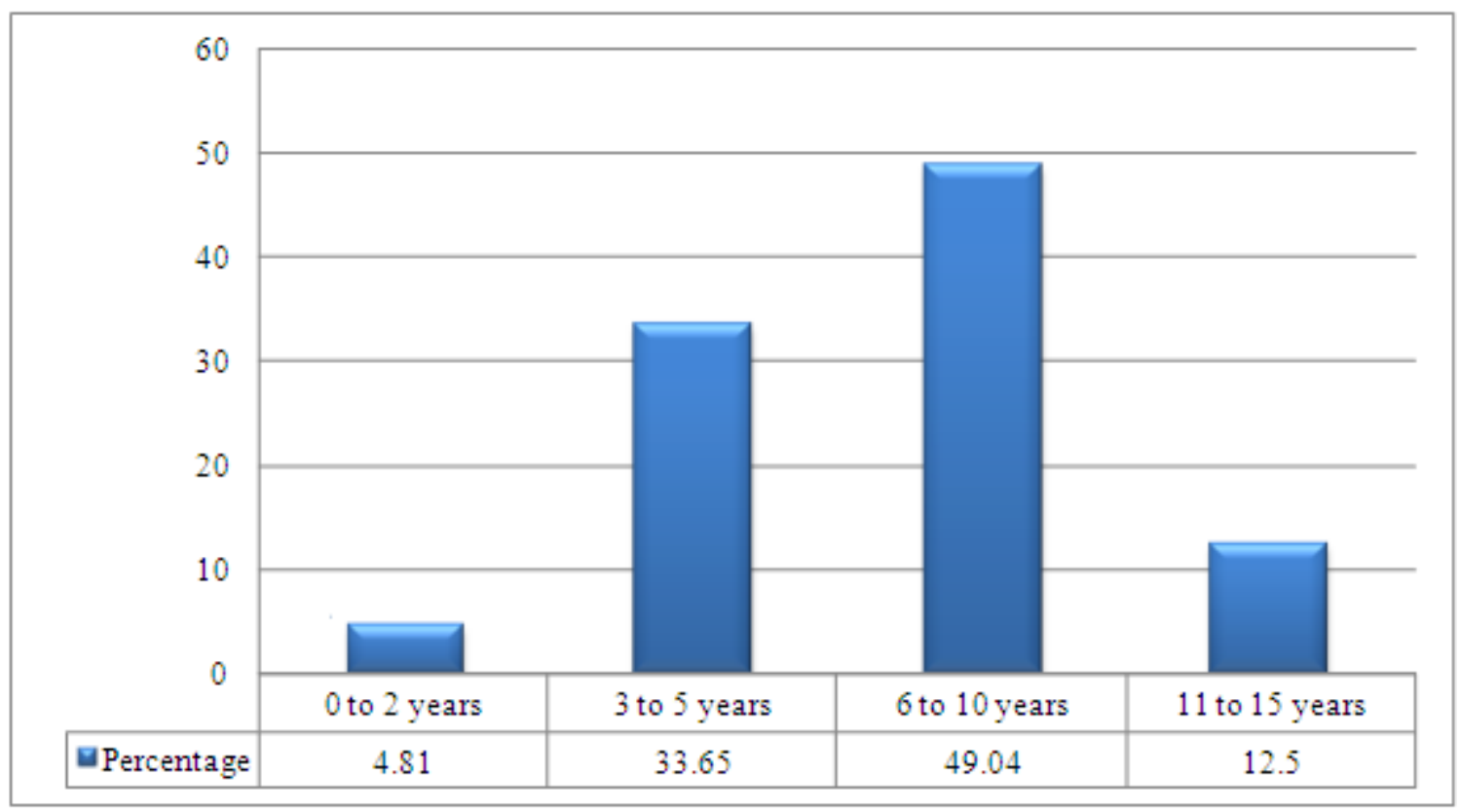

Figure 1. The duration of survival of emerging contractors in Limpopo.

It can be seen from Figure 2 that $42.2 \%$ of contractors have managed to obtain Grade 12 (matric) certificates. The figure also shows that $21.12 \%$ of contractors have obtained diplomas, and that only $3.68 \%$ of them have earned postgraduate level academic qualifications. Figure 2 shows that the number of qualifications sharply declines as one goes to postgraduate level qualifications. This trend is consistent with the difficulties involved with acquiring high level qualifications in the construction industry. The information presented in Figure 2 indicates that emerging and black entrepreneurs in the construction industry of Limpopo Province are characterized by lack of advanced technical and engineering related skills.

Figure 3 shows that the percentage of contractors holding CIDB qualifications of grade 5 is equal to $25 \%$. The corresponding figures for grades 6 and 7 CIDB qualifications are 24.04\% and 6.73\% respectively. The figures for grade 2 (19.23\%), grade 3 (8.65\%), and grade 4 (16.35\%) show that it is essential to improve CIDB grades of emerging contractors before they can compete for sustainable operations as well as large scale construction projects. The use of development programmes is viewed as pivotal for unlocking the full potential of small and emerging contractors in the construction industry of Limpopo Province. 


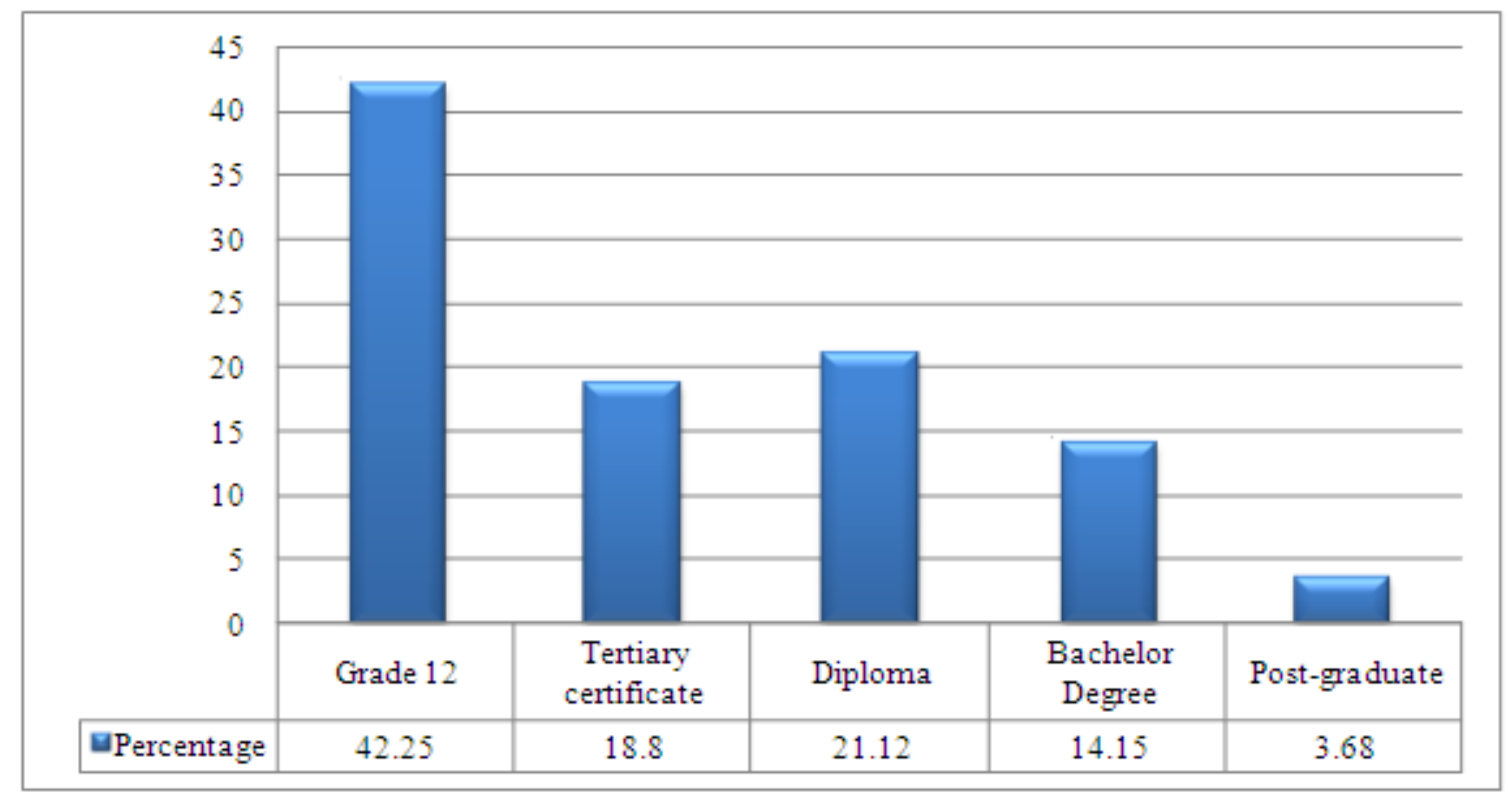

Figure 2. Academic qualifications of contractors.

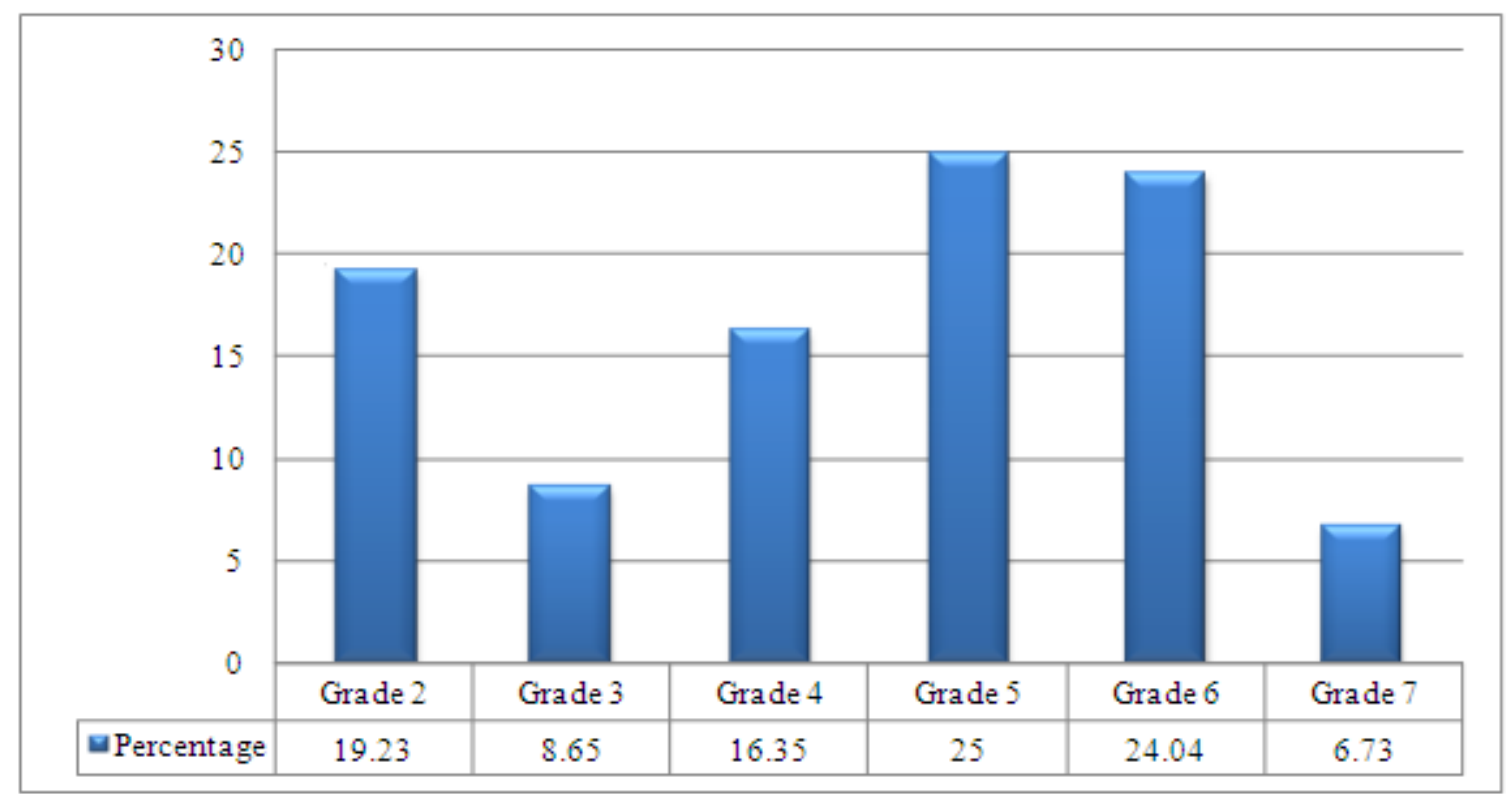

Figure 3. CIDB grades of emerging contractors.

\section{Factors That Affect the Performance of Contractors}

Figure 4 shows that $78.85 \%$ of contractors have had to frequently change their original scopes of work due to challenges. Undoubtedly, such changes have the ability to obstruct plans that have been put forward by the contractor in executing the project. Delays in the approval of construction and working plans were experienced by $65.38 \%$ of emerging contractors illustrating inefficiency of some clients to ensure that projects are delivered on time and within allocated budget. Figure 4 also shows that $60.58 \%$ of contractors experienced problems related to technical matters. Typically, unforeseen technical challenges that are encountered in the course of contractual work have severe negative consequences in emerging contractors. This problem is further 
aggravated by the appointment of unregistered engineers with relevant professional bodies to design and supervise emerging contractors.

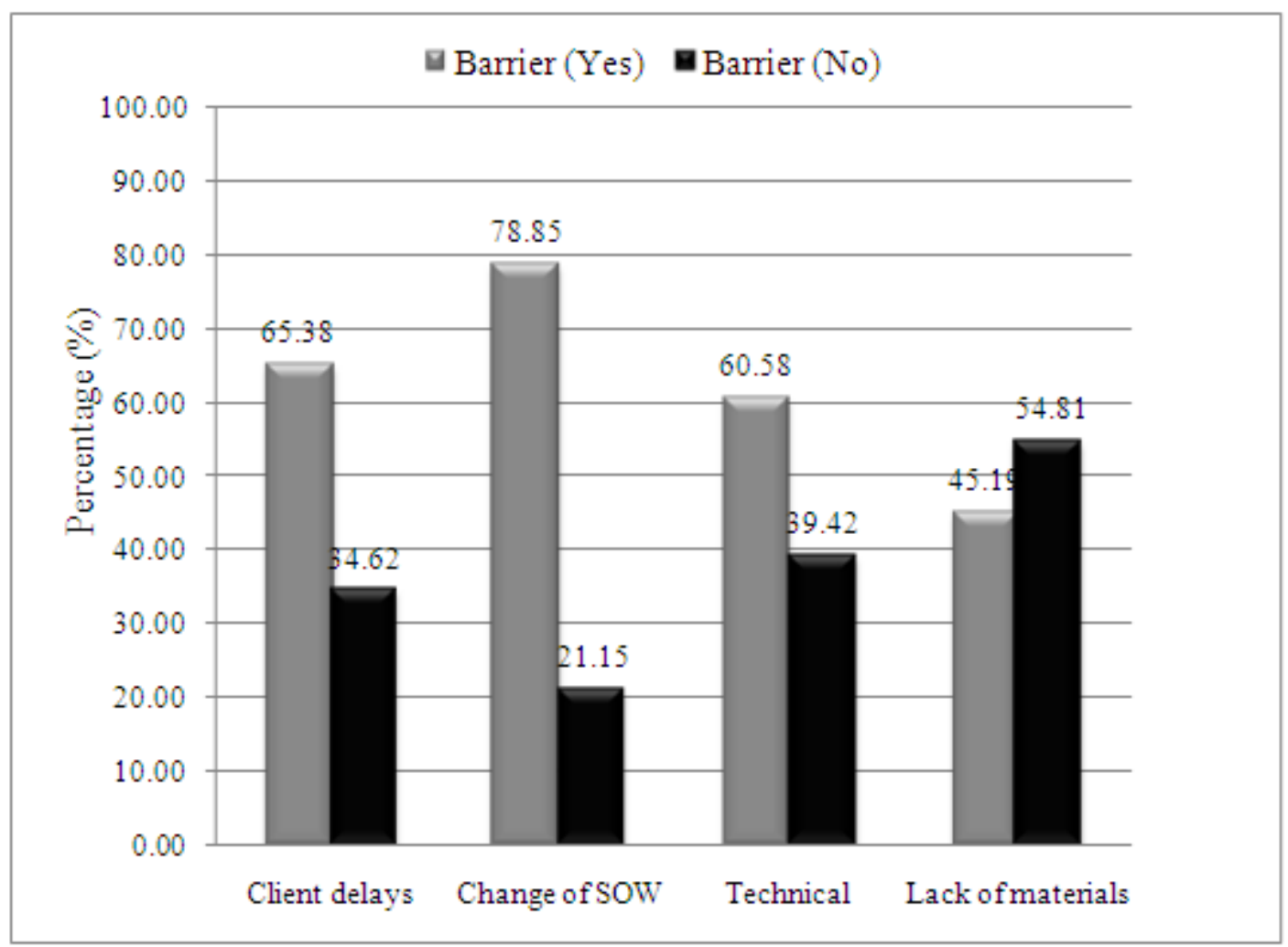

Figure 4. Factors that affect the performance of contractors.

Figure 5 shows that $76.92 \%$ of contractors are normally affected by an increase in the cost of plants. The nature of the construction business is that emerging contractors are significantly affected by sudden increases in costs. Escalating costs often put contractors out of business. Emerging contractors are more vulnerable to increases in cost because they often fail to hire plants at reasonable market rates. They often pay higher costs to companies that lease plants because of failure to conduct research on the affordability of costs. Figure 5 further shows that $53.85 \%$ of participants experienced difficulties in acquiring construction materials. More often than not, the cost of materials increases when there is a shortage of supply in the market. Emerging contractors are severely affected by the scarcity of construction materials in the market. Such obstacles often prevent emerging contractors from competing with well-established companies successfully.

\section{Pearson's Chi-square Tests of Associations}

This section presents a summary of significant associations obtained from Pearson's chi-square tests of associations. At the $5 \%$ level of significance, significant relationships are characterized by $P$-values that are smaller than 0.05. Table 3 shows that lack of vision for business, lack of strategy for business, and lack of productivity were all significantly associated with the failure of construction companies. Lack of visionary leadership in businesses could be attributed to lack of aspiration by the owners. This could be attributed to the inability of emerging contractors to provide strategic leadership on their own due to lack of technical and entrepreneurial skills. Poor production output is attributed to lack of competencies to execute contracts effectively and efficiently. 


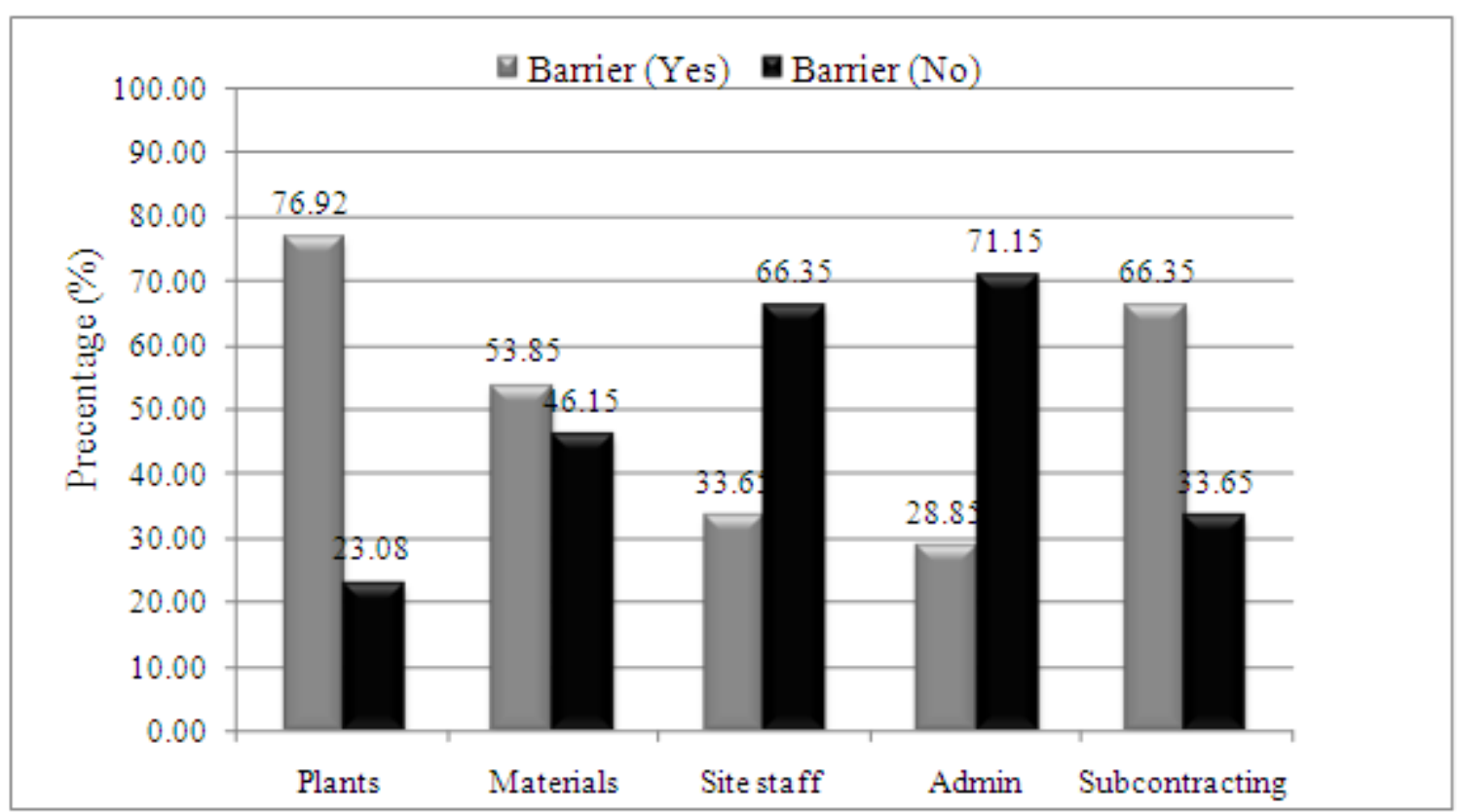

Figure 5. Increase in costs that affect the performance of contractors.

Table 3

The Impact of Lack of Vision, Lack of Strategy, and Poor Production Output

\begin{tabular}{|c|c|c|c|c|c|c|c|c|c|}
\hline \multirow{2}{*}{ Failure } & \multicolumn{3}{|c|}{ Lack of vision for business } & \multicolumn{3}{|c|}{ Lack of strategy } & \multicolumn{3}{|c|}{ Lack of production } \\
\hline & No & Yes & Total & No & Yes & Total & No & Yes & Total \\
\hline \multirow[t]{3}{*}{ No } & 22 & 7 & 29 & 49 & 9 & 58 & 50 & 8 & 58 \\
\hline & 10.6 & 18.4 & 29.0 & 39.6 & 18.4 & 58.0 & 38.5 & 19.5 & 58.0 \\
\hline & 21.15 & 6.73 & 27.88 & 47.12 & 8.65 & 55.77 & 48.08 & 7.69 & 55.77 \\
\hline \multirow[t]{3}{*}{ Yes } & 16 & 59 & 75 & 22 & 24 & 46 & 19 & 27 & 46 \\
\hline & 27.4 & 47.6 & 75.0 & 31.4 & 14.6 & 46.0 & 30.5 & 15.5 & 46.0 \\
\hline & 15.38 & 56.73 & 72.12 & 21.15 & 23.08 & 44.23 & 18.27 & 25.96 & 44.23 \\
\hline \multirow[t]{4}{*}{ Total } & 38 & 66 & 104 & 71 & 33 & 104 & 69 & 35 & 104 \\
\hline & 38.0 & 66.0 & 104.0 & 71.0 & 33.0 & 104.0 & 69.0 & 35.0 & 104.0 \\
\hline & 36.54 & 63.46 & 100.00 & 68.27 & 31.73 & 100.00 & 66.35 & 33.65 & 100.00 \\
\hline & \multicolumn{3}{|c|}{$\begin{array}{l}\text { Pearson chi 2(1) = 26.8194, } \\
\operatorname{Pr}=0.000\end{array}$} & \multicolumn{3}{|c|}{$\begin{array}{l}\text { Pearson chi } 2(1)=15.9130 \\
\operatorname{Pr}=0.000\end{array}$} & \multicolumn{3}{|c|}{$\begin{array}{l}\text { Pearson chi 2(1) = 23.1656, } \\
\operatorname{Pr}=0.000\end{array}$} \\
\hline
\end{tabular}

Table 4 shows that financial constraints, lack of project management skills, and lack of entrepreneurial skills are all significantly associated with the failure of construction businesses at the 5\% level of significance. Due to poor financial management and lack of collateral to access financial support from lenders, emerging contractors are difficult entities to run without recurring challenges. Also of prime importance is that successful contractors are expected to possess basic project management skills. As a result of lack of project management skills, emerging contractors find themselves not meeting key project targets. The challenges that emerged as a result of inadequate entrepreneurial skills were also highlighted in Table 4. Accordingly, entrepreneurial skills are related to marketing skills, and affect the ability of emerging contractors to make use of opportunities in the market. 
Table 4

The Impact of Financial Constraints, Poor Project Management Skills, and Lack of Entrepreneurial Skills

\begin{tabular}{|c|c|c|c|c|c|c|c|c|c|}
\hline \multirow{2}{*}{ Failure } & \multicolumn{3}{|c|}{ Financial constraint } & \multicolumn{3}{|c|}{ Lack of project management skill } & \multicolumn{3}{|c|}{ Lack of entrepreneurial skill } \\
\hline & No & Yes & Total & No & Yes & Total & No & Yes & Total \\
\hline \multirow[t]{3}{*}{ No } & 58 & 0 & 58 & 18 & 11 & 29 & 21 & 8 & 29 \\
\hline & 32.3 & 25.7 & 58.0 & 10.3 & 18.7 & 29.0 & 10.6 & 18.4 & 29.0 \\
\hline & 55.77 & 0.00 & 55.77 & 17.31 & 10.58 & 27.88 & 20.19 & 7.69 & 27.88 \\
\hline \multirow[t]{3}{*}{ Yes } & 0 & 46 & 46 & 19 & 56 & 75 & 17 & 58 & 75 \\
\hline & 25.7 & 20.3 & 46.0 & 26.7 & 48.3 & 75.0 & 27.4 & 47.6 & 75.0 \\
\hline & 0.00 & 44.23 & 44.23 & 18.27 & 53.85 & 72.12 & 16.35 & 55.77 & 72.12 \\
\hline \multirow[t]{4}{*}{ Total } & 58 & 46 & 104 & 37 & 67 & 104 & 38 & 66 & 104 \\
\hline & 58.0 & 46.0 & 104.0 & 37.0 & 67.0 & 104.0 & 38.0 & 66.0 & 104.0 \\
\hline & 55.77 & 44.23 & 100.00 & 35.58 & 64.42 & 100.00 & 36.54 & 63.46 & 100.00 \\
\hline & \multicolumn{3}{|c|}{$\begin{array}{l}\text { Pearson chi } 2(1)=104.0000, \\
\operatorname{Pr}=0.000\end{array}$} & \multicolumn{3}{|c|}{$\begin{array}{l}\text { Pearson chi } 2(1)=12.3138, \\
\operatorname{Pr}=0.000\end{array}$} & \multicolumn{3}{|c|}{$\begin{array}{l}\text { Pearson chi } 2(1)=22.3204, \\
\operatorname{Pr}=0.000\end{array}$} \\
\hline
\end{tabular}

Table 5

Demographic, Political and Good-Governance Issues Adversely Affecting Viability

\begin{tabular}{|c|c|c|c|c|c|c|c|c|c|}
\hline \multirow{2}{*}{ Failure } & \multicolumn{3}{|c|}{ Demographic problems } & \multicolumn{3}{|c|}{ Adverse political environment } & \multicolumn{3}{|c|}{ Lack of transparency } \\
\hline & No & Yes & Total & No & Yes & Total & No & Yes & Total \\
\hline \multirow[t]{3}{*}{ No } & 23 & 6 & 29 & 13 & 16 & 29 & 9 & 20 & 29 \\
\hline & 12.5 & 16.5 & 29.0 & 4.5 & 24.5 & 29.0 & 8.1 & 9 & 29.0 \\
\hline & 22.12 & 5.77 & 27.88 & 12.50 & 15.38 & 27.88 & 8.65 & 19.23 & 27.88 \\
\hline \multirow[t]{3}{*}{ Yes } & 22 & 53 & 75 & 3 & 72 & 75 & 5 & 70 & 75 \\
\hline & 32.5 & 42.5 & 75.0 & 11.5 & 63.5 & 75.0 & 7.9 & 67.1 & 75.0 \\
\hline & 21.15 & 50.96 & 72.12 & 2.88 & 69.23 & 72.12 & 5.92 & 76.19 & 72.12 \\
\hline \multirow[t]{4}{*}{ Total } & 45 & 59 & 104 & 16 & 88 & 104 & 11 & 93 & 104 \\
\hline & 45.0 & 59.0 & 104.0 & 16.0 & 88.0 & 104.0 & 11.0 & 93.0 & 104.0 \\
\hline & 43.27 & 56.73 & 100.00 & 15.38 & 84.62 & 100.00 & 10.58 & 89.42 & 100.00 \\
\hline & \multicolumn{3}{|c|}{$\begin{array}{l}\text { Pearson chi } 2(1)=21.2799 \\
P r=0.000\end{array}$} & \multicolumn{3}{|c|}{$\begin{array}{l}\text { Pearson chi } 2(1)=26.7792, \\
\operatorname{Pr}=0.000\end{array}$} & \multicolumn{3}{|c|}{$\begin{array}{l}\text { Pearson chi } 2(1)=17.7938 \\
\operatorname{Pr}=0.005\end{array}$} \\
\hline
\end{tabular}

Table 5 shows that demographic problems, adverse political environment, and lack of transparency in tender processes are all significantly associated with the failure of emerging contractors. Because of demographic challenges, emerging contractors in Limpopo are reluctant to seek opportunities elsewhere. When emerging contractors reach a certain stage of maturity, they will be required to enter other markets. To do so, they need to have the necessary finance, resources, and expertise. The presence of a stable political environment is an important predictor of viability in small businesses. As illustrated in Table 5, adverse political environment has the potential for stifling emerging contractors who do not have political connections. Lack of transparency in the award of tenders is often a result of failure to provide political leadership of the Provincial Government of Limpopo. Corruption and bribery must be discouraged and severely punished by relevant authorities assigned such responsibilities in order to encourage potential construction entrepreneurs to promote economic growth and sustainable employment. 


\section{Results Obtained From Factor Analysis and Binary Logistic Regression Analysis}

Table 6 shows estimated Eigenvalues and percentage of explained variation for three influential predictors of viability in emerging contractors. Each of the estimated Eigenvalues is significantly greater than one. It can be seen from the table that the total variance explained by these three factors is equal to $77.86 \%$, a figure which is above $75 \%$. This indicates that the three extracted factors collectively account for variability in the viability of emerging contractors fairly well.

Table 6

Eigenvalues and Variance Components Estimated From Factor Analysis

\begin{tabular}{llll}
\hline Extracted actor & Eigenvalue & $\begin{array}{l}\text { Percentage of explained } \\
\text { variance in viability }\end{array}$ & Cumulative percentage of explained variation \\
\hline Lack of entrepreneurial skills & 4.115 & 34.213 & 34.213 \\
Lack of capital & 3.596 & 24.556 & 58.769 \\
Lack of transparency in the award & 2.887 & 19.089 & 77.858 \\
\hline
\end{tabular}

Odds ratios were estimated from binary logistic regression analysis. These estimates were quite similar to estimates obtained from factor analysis, and showed that viability in emerging contractors was significantly influenced by lack of entrepreneurial skills, lack of capital, and lack of transparency in the award of construction tenders, in a decreasing order of strength.

\section{Results Obtained From Multilevel Analysis}

Table 7 shows covariance parameter estimates obtained from multilevel analysis. The results show that differences among the five districts of Limpopo account for $13.18 \%$ of total variability in viability. Differences related to entrepreneurial skills account for $33.49 \%$ of total variability in viability.

Table 7

Components of Variance Estimated From Multilevel Analysis

\begin{tabular}{lll}
\hline Variance & Estimate & $P$-value \\
\hline Districts & 0.1538 & 0.0000 \\
Entrepreneurial skills & 0.3908 & 0.0000 \\
Error & 0.6223 & 0.1416 \\
Total variance & 1.1669 & \\
\hline
\end{tabular}

\section{Conclusions}

The study has managed to reveal the challenges that persist to deny emerging contractors a room towards sustainable development and prosperity in Limpopo Province. Results obtained from Pearson's chi-square tests of associations have shown that the viability of emerging contractors in the construction industry of Limpopo Province and their ability to increase their current degree of access to the construction market are significantly influenced by the following factors: lack of vision for business, lack of strategy for business, poor productivity or inefficiency, lack of access to finance on favourable terms, lack of project management skills, and lack of entrepreneurial skills. Furthermore, variables such as demographic challenges, adverse political environment, and lack of transparency in tender processes were also identified to play a significant contribution to the success of small and emerging contractors in Limpopo Province. Based on the results obtained from multilevel analysis, differences among the five districts of Limpopo Province account for $13.18 \%$ of the total variation. 
Differences in entrepreneurial skills between viable and non-viable businesses account for $33.49 \%$ of the total variation.

\section{Recommendations}

Based on the key findings of the study, the following recommendations are made so that where possible, feasible measures could be taken in order to improve the plight of emerging contractors operating in the construction industry in Limpopo Province. The recommendations are quite helpful for addressing deficiencies that are inherent in the current regulatory framework governing operations conducted by small enterprises, and create an economic enabling environment for emerging contractors.

\section{Adopting an Entrepreneur-Orientated Contractor Development Model}

The study has found that the curriculum used in Contractor Development Programmes (CDPs) does not enable emerging contractors to acquire and improve their entrepreneurial and engineering related technical skills. The curriculum must be revised so that emerging contractors can be educated on how to develop business plans, how to grow their business, how to formulate long-term strategy for business, how to conduct audits, and how to write progress reports on construction projects. It is perceived that this will enable the CIDB to improve its quality of services to emerging contractors.

\section{Enforcing a Code of Good Conduct From Various Stakeholders}

Lack of transparency and accountability in the award of tenders has severely affected new entrants into the construction market (Bates, 2013). The practice is stifling the growth and development of emerging contractors who lack political connection. Unethical conducts often influence the outcome of tender processes in the construction industry in the Limpopo Province. Such a practice often disadvantages small and emerging contractors who hope to conduct business openly. Thus, it is highly recommended that the CIDB enforce a suitable code of conduct to protect and safeguard good business practice.

\section{Instituting a Curriculum Review in Engineering Related Academic Qualifications}

The study has found that graduates of engineering often lack practical skills at the marketplace due to lack of relevance of the academic curriculum to what is needed at the marketplace. For this reason, it is necessary to institute a curriculum review at the Faculty of Engineering of the University of Limpopo. This recommendation is in line with the national skills development plan of South Africa-The Creation of Positive Political Environment in Limpopo Province.

\section{The Creation of an Enabling Political Environment}

The study found that political interference in tender processes is currently stifling growth in emerging contractors in Limpopo Province. In view of the fact that the construction industry is an economic sector that has the potential for creating a large number of labour-intensive job opportunities for the unemployed, the Provincial Government of Limpopo must make sure that tender procedures are fair, objective, and transparent.

\section{References}

Bates, C. (2013). Corporate governance is for small business too. Pretoria: South Africa.

Construction Industry Development Board (CIDB). (2010). Targeting for contractor development programmes: Background. Retrieved May 15, 2013, from http://www.cidb.org.za/documents/kc/cidb_publications/ind_reps_other/ind_reps_target Dawson, B. K., \& Trapp, R. G. (2004). Basic clinical biostatistics (2nd ed.). New York: McGraw-Hill.

Field, A. (2010). Discovering statistics using SPSS (3rd ed.). London: Sage Publications. 
Hosmer, D. W., \& Lemeshow, S. (2002). Applied logistic regression analysis. New York: John Wiley and Sons.

Human, D. (2006). Implementation of affirmative action and black economic empowerment (BEE) in the construction industry: A paper for the quantity surveying industry. Retrieved May 15, 2013, from http://www.icoste.org/ASAQS_Human.pdf

Ncwadi, M. R., \& Dangalazana, T. (2005). An exploratory study into the challenges facing the emerging contractors involved in the construction of low cost housing in Wells Estate and Ikamv'elihle townships in the Nelson Mandela Metropole, South Africa. Proceedings from the World Congress on Housing, Transforming Housing Environments Through Design (pp. 27-30). Pretoria.

Rabe-Hesketh, S., \& Skrondal, A. (2008). Multilevel and longitudinal modelling using STATA (2nd ed.). Texas: STATA Press.

Smit, Y., \& Watkins, J. A. (2012). A literature review of small and medium enterprises (SME) risk management practices in South Africa. African Journal of Business Management, 6(21), 6324-6330.

Smith, C. J., Oosthuizen, R., Harris, H., Venter, J. P., Combrink, C., \& Roodt, J. H. S. (2012). System of systems engineering-The link between operational needs and system requirements. South African Journal of Industrial Engineering, 23(2), 47-60.

STATA Corporation. (2011). User's guide for STATA. College Station: STATA Corporation.

Statistics South Africa. (2007). Construction industry. Retrieved May 15, 2013, from http://www.statssa.gov.za

Thwala, W. D., \& Phaladi, M. J. (2009). An exploratory study of problems facing small contractors in the north west province of South Africa. African Journal of Business Management, 3(10), 533-539.

Tshivhase, K. L. (2007). An investigation into the management issues that affect the growth and development of SMME's in the construction industry in Polokwane: Limpopo Province. Durban: Management College of Southern Africa. 